\title{
SHORT WAVE RECEIVERS AND THE FOREIGN LANGUAGE TEACHER
}

\author{
by Dale V. Lally
}

The current proliferation of audio-visual devices for use in the foreign language classroom appears to have bypassed one relatively inexpensive yet very useful tool, namely, the high frequency or short wave receiver. When Norman Mikesell designed the language laboratory facilities here at Marquette University just a few short years ago, being a practical man he naturally included just such a receiver. Its primary function remains the reception of foreign language broadcasts. Such programs, particularly newscasts, offer several outstanding advantages over commercially produced tapes, not the least of which is immediacy. It is the nature of newscasts to contain the very latest in world events using the contemporary spoken languages. Since each individual language represents a different view of reality, then the foreign language newscasts always present the listener with a version of world events which is somewhat different from the version expressed in his native tongue. It remains the contention of the author that topical short wave materials, when effectively presented to the class, will not only complement existing textual materials, but also stimulate discussion and provide a ready vehicle for material introduction, review, and testing. However, while it remains a simple task to connect a tape recorder to a short wave receiver and record transmissions right off the air, there are three areas of difficulty associated with such an operation: (1) the selection of the short wave receiver, (2) the broadcast timetable and usable frequencies, and (3) the problem of actual classroom utilization of recorded shortwave materials.

\section{Selecting A Short Wave Receiver}

Having had experience both as an amateur radio operator (WOWF) and as an airborne radio operator in the Navy, I cannot overstress the utility of a sensitive, highly selective, and versatile general coverage communications receiver. New consumer oriented receivers of the quality suitable for this purpose generally start at around $\$ 200$ and could run into thousands of dollars. However, if your school is fortunate enough to sponsor an amateur radio club, I am certain that the club will be most cooperative in either permitting the foreign language teacher to use the club receiver (if it covers the required frequencies) or assisting in the selection and use of a receiver. The device chosen for this project must be able to tune the major foreign broadcast bands on 6, 9, 12, 16, and 18 Megaherz (Mhz). 


\section{Short Wave Receivers}

Another foreign broadcast band on $22 \mathrm{Mhz}$ generally offers fairly good reception but there are a few surplus military receivers which are unable to tune this latter frequency.

In addition to the above stated operational range, the teacher should insist that the receiver have a bandspread for fine tuning, a noise limiter, an automatic gain control (AGC), separate radio frequency (RF) and audio frequency (AF) gain controls, and a transmitreceive (standby) switch. The latter can be very important, particularly if the receiver is an older tube type rather than solid state. Putting the switch on transmit (or standby) permits the operator to leave the tube filaments turned on but without the dangerous high voltage being present in the receiver. Permitting the filaments to remain lighted not only increase frequency stability but actually extends life of the tubes.

Commercial sources for short wave receivers are many and varied. As stated earlier, new receivers of fairly good quality may be purchased for around $\$ 200$, the inexpensive models being made by Hallicrafters and Hammarlund. However, it is my own opinion (albeit very subjective) that inexpensive consumer type receivers will just not hold up in the face of continued hard usage. It is at this point that I would like to suggest that the prospective buyer consult the surplus military receiver market. A recent catalogue from a surplus house in Ohio offered several excellent surplus military receivers at just a fraction of their original cost. A few examples of models and prices are: 1) a BC-348 general coverage receiver which tunes the A.M. broadcast band and six additional shortwave bands from $200 \mathrm{Kiloherz}(\mathrm{Khz})$ to $18 \mathrm{Mhz}$ was only $\$ 110$ complete with power supply; 2) an RCAF GR-10, tunable to $31 \mathrm{Mhz}$, was only $\$ 90 ; 3$ ) an RCA AR-88, for frequencies to $32 \mathrm{Mhz}$ was \$165; while (4) the excellent Hammarland SP-600 was priced at $\$ 275$. Again it must be pointed out that these prices represent only a fraction of the original purchase price charged to the government. Another concrete advantage of surplus military gear is the fact that it is designed to operate for long periods at less than optimum conditions requiring little maintenance and the simplest of test equipment. This latter can be a crucial point particularly in small schools where A.V maintenance is often left to the physics teacher or even the custodial staff.

Another possible source of assistance in the procurement of surplus military equipment could be the local station of the Military Affiliate Radio System (MARS), which are usually very busy operations, particularly on air force bases. If there are no MARS stations in your vicinity, check with the local amateur radio crowd for assistance. 


\section{The Art of Short Wave Listening (SWL'ing)}

Discovering the times and frequencies of useful short wave foreign language broadcasts remains a relatively easy task, if for no other reason than the fact that the sponsoring agencies do spend an enormous amount of money on facilities, production and publicity, and they do want someone to listen to their programs every once in a while. This subject comes under the heading of Short Wave Listening and most of the popular electronics periodicals devote sections to the SWL'ers, giving the times and frequencies of the usual and sometimes unusual short wave broadcasts. Though the information is normally given for English language broadcasts, the frequencies remain relatively unchanged and often addresses are given where interested listeners may request further information on foreign language transmissions. Finally, a short note of inquiry to the Washington embassies of various foreign countries will bring courteous thank you notes and helpful information on foreign and English language broadcasts. However, it is very likely that such a circuitous route might not be necessary.

The Hammarlund HQ 100 general purpose short wave receiver in the control room of the Marquette University Foreign Language Laboratories constantly picks up usable broadcasts in all languages and at various times throughout the normal working day. It was not necessary to write letters of inquiry to any station, but rather a regular sweep of the high frequency spectrum at regular intervals revealed foreign language broadcasts in just about every foreign language taught here at Marquette. The Voice of America (VOA) broadcasts in German every day at 8:45 CDST on the $15 \mathrm{Mhz}$ band, while radio Canada transmits a daily German language program including news and features on approximately the same frequency as VOA but at 12:45 CDST. French language broadcasts can be heard at various times throughout the day from both Radio Canada and the Voice of South Africa. In Spanish there are several consistently good sources including the Voice of America, Radio Mexico International, and even Radio Havana. All the above mentioned stations can be received quite clearly throughout the day on the $16 \mathrm{Mhz}$ broadcast band. Radio Mexico, for instance, trasmits with one million watts power on 9.705, 11.770, 17.835 and 21.705 Mhz. Germany's Deutsche Welle may occasionally be heard in the daytime on the $16 \mathrm{Mhz}$ band, but the evening remains the optimum time for reception of the Deutsche Welle north american service. Very often the evening hours will bring in many different foreign language broadcasts simultaneously. This is a situation requiring a competent operator at the receiver controls, who not only knows how to properly manipulate the various crystal and noise filters for clear reception, but also can connect the receiver audio output to the tape recorder input to record the received signal. Solving 


\section{Short Wave Receivers}

the question of receiver acquisition, program reception and recording leads directly into the thorniest aspect of the project, namely, the effective classroom use of the recorded short wave materials.

\section{Classroom Utilization}

Most teachers will agree that a certain amount of excitement and expectation always accompanies the beginning of a new school year or the introduction of a new text or program-well almost always. If remains an unfortunate fact that often a teacher will be saddled with a text for which he has little regard or confidence. And there are many instances where small school systems, operating on tight budgets, can afford textual changes every four or five years. This can be very depressing for students and teachers alike. These and other problems can often be ameliorated or solved through the use of supplementary short wave materials.

The nature of radio programming being what it is, broadcast materials are changed daily, often hourly, and can be used to effectively upgrade just about any existing text. After all, grammar rules remain static, regardless of the text in use, while some texts merely present the grammar better than others. The use of short wave materials offers several advantages, primarly topicality and vocabulary. Certainly very few existing texts present any sort of space age vocabulary such as lunar module, earth orbit or moon rover. Topical subjects and vocabulary offer many starting points for instruction. German language newscasts, for instance, while mostly in the third person, offer many excellent examples of indirect discourse, the subjunctive mood, and word order problems in dependent clauses. Certainly classroom grammar instruction can easily revolve around the vocabulary, news items and grammatical constructions included in the broadcasts. Thus the teacher may still introduce new materials while bound to an older text. Following is a practical suggestion on the collection and utilization of such materials.

Let us assume that it is Monday afternoon and John $Q$ Teacher, an instructor in German and History at a small midwestern high school, has spent the first few minutes of his 11:30 to 12:30 planning period connecting the school's surplus SP 600 receiver to his own recorder which he brought from home just for this project. After checking out all the connections he is now prepared to record whatever comes through the speaker. He is tuned to the proper frequency in the 15 Mhz band and at precisely 11:43 CST, a voice from radio Canada announces the end of the daily Czech language broadcast and gives the time for the next Czech program. Then, immediately after the announcer says "Ici Radio Canada, this is Canada," come the familiar musical notes which always identify Radio Canada. After listening to the chimes strike four times, the teacher turns on his recorder just in 
time to record the following: "Guten Abend, liebe Horer, hier spricht Kanada. Der Auslandsdienst Radio Kanadas etc., etc., etc." The opening ten minutes are devoted to a newscast and will probably include stories about Viet Nam, youthful demonstrators, or the latest crisis along the Suez canal. Following the news are twenty minutes of music and features. At 12:15 CST the German language ends and the teacher has taped thirty minutes of the latest news and features in German. Still the question remains as to what to do with it and how.

For his own benefit the teacher must immediately replay the first few minutes of the tape in order to pick out difficult vocabulary words and grammatical constructions. As a matter of fact, the instructor will probably encounter a few German words which he had never before heard and must look them up in the dictionary for his own benefit and information. There is certainly no harm or shame in doing that. After this quick preview of the news segment of the tape, the teacher is ready to present the newscast to his very next intermediate German class which meets at 12:30.

He begins the class with a full replay of the lead story which probably runs less than forty-five seconds. He then stops the recorder and asks the students questions on the content and any familiar words. After figuring the general idea of the story, the lead story is then replayed in very, very short segments, often single words or short phrases. Slowly, word by word and phrase by phrase, the teacher assists his students in repeating what they have heard on the tape, while simultaneously pointing out new vocabulary and difficult constructions. At the same time the teacher continually puts questions to his class, questions which, though in content are a part of the news story, actually constitute a review of previously covered items and a subtle introduction of new material. After devoting just a few minutes to the lead story including a review of previously covered material, an introduction of new items, and comprehensive questions on the content of the newscast, the teacher is ready with a new challenge.

Rewinding the tape back to the beginning, the students are instructed to write the story down on paper as it is played in short segments. This dictation could be utilized in several ways. Several students could write their dictations on the blackboard for class discussion and/or correction. The teacher could even project a couple of student papers onto the wall with the ever ready opaque projector, pointing out mistakes, reviewing materials and introducing new concepts. Unfortunately, many opaque projectors generate a fair amount of noise. To solve this problem, the instructor could type out the text, make a transparency, and use an overhead projector to present his own correct version. Ending the short wave segment of the class, the instructor informs his students that, in addition to their regular home- 


\section{Short Wave Receivers}

work from the grammar text, portions of the recorded newscast will be assigned for dictation and as test material. A quiz on this material could include specific questions on the content, oral student response to questions put forth by the teacher or even a rewriting of the content-all in German. To aid the student in preparation for the quiz, the teacher informs his students that a taped copy of the entire program will be made available for individual listening in the library A-V carrel. And over the next few days, the teacher covers the segments of the broadcast he intends to use on the quiz.

Thus with proper classroom presentation and a small portion of class time (say twenty minutes daily), the short wave receiver has provided recorded materials which not only complement existing materials, but also stimulate discussion and provide a ready vehicle for introduction, review and testing.

During this past summer of 1971 , just such an experiment as described above was actually carried out in the Marquette University third and fourth semester German classes. At the request of the regular instructor, the author collected, edited, prepared and actually presented the materials to the class. Using a time teaching approach, recordings and transparencies were used in the class and rudimentary testing devices were formulated. Both students and instructors deemed the experiment gratifying and worthwhile. This experiment will be described in an article entitled "Teaching German via Short Wave Broadcasts" currently being prepared for publication. The Fall 1971 semester has seen a continuation of the experiment using the German intermediate honors section. After just a few weeks of experimentation, notable results have already been observed in oral comprehension, production and motivation.

An obvious sequal to this experiment would be the introduction of videotape materials for classroom use. This should include the foreign language versions of the television standards "Bonanza", "The Men from Shiloh" or even "Peyton Place". Furthermore the foreign language videotaped versions of such motion picture classics as "Stagecoach" or "West Side Story" could also be effectively used in a classroom situation. Certainly the time has come for foreign language teachers to realize that to capture the attention and enthusiasm of our students and provide a strong motivation to continue foreign language studies, we must not only make the classroom presentation more topical and lively, but we must also learn to use the students' own background as a starting point for instruction.

ABOUT THE AUTHOR:

Mr. Lally is Director of Foreign Language Laboratories, Marquette University, Milwaukee, Wisconsin. 


\section{Zum ersten mal.. Por primera vez.. Per la prima volta... Pour la première...}

\section{... For the first time...}

SONY LEARNING LABORATORY SYSTEMS are now available in the United States!

And that's good news ... whether you're just getting started with learning laboratory systems ... or preparing to update your present facilities.

Now you can have the SONY LL. Systems that have been utilized for the past 15 years throughout the world from $A$ to $Z$ Auckland Grammar School in New Zealand to the Universidad de Zulia in Venezuela). SONY LL Systems ranging from the lowcost manually-operated cassette student booth recorders to remote-controlled cassette student booth recorders . . . plus sophisticated automated audio-visual LL and economical audio-active LL systems, as well . . . backed by SONY quality and
SONY reliability. LL systems whose component parts: microphones, transistors, motors, heads, etc., are designed ... manufactured ... tested ... quality-controlled and assembled by SONY. In SONY'S own plants!

LL systems designed to give the user dependable performance and the dealer happy customers. For more information on SONY LL Systems, write to: SONY CORPORATION OF AMERICA, LL Systems Dept., 47-47 Van Dam Street, Long Island City, N. Y. IIIOI. (212) 361-8600.

And ... IF YOU WANT TO BE A DEALER for SONY LL Systems and get in on the ground floor of a growing communications facet... please make all inquiries to $\mathrm{Mr}$. $W$. Tucker at the above address.
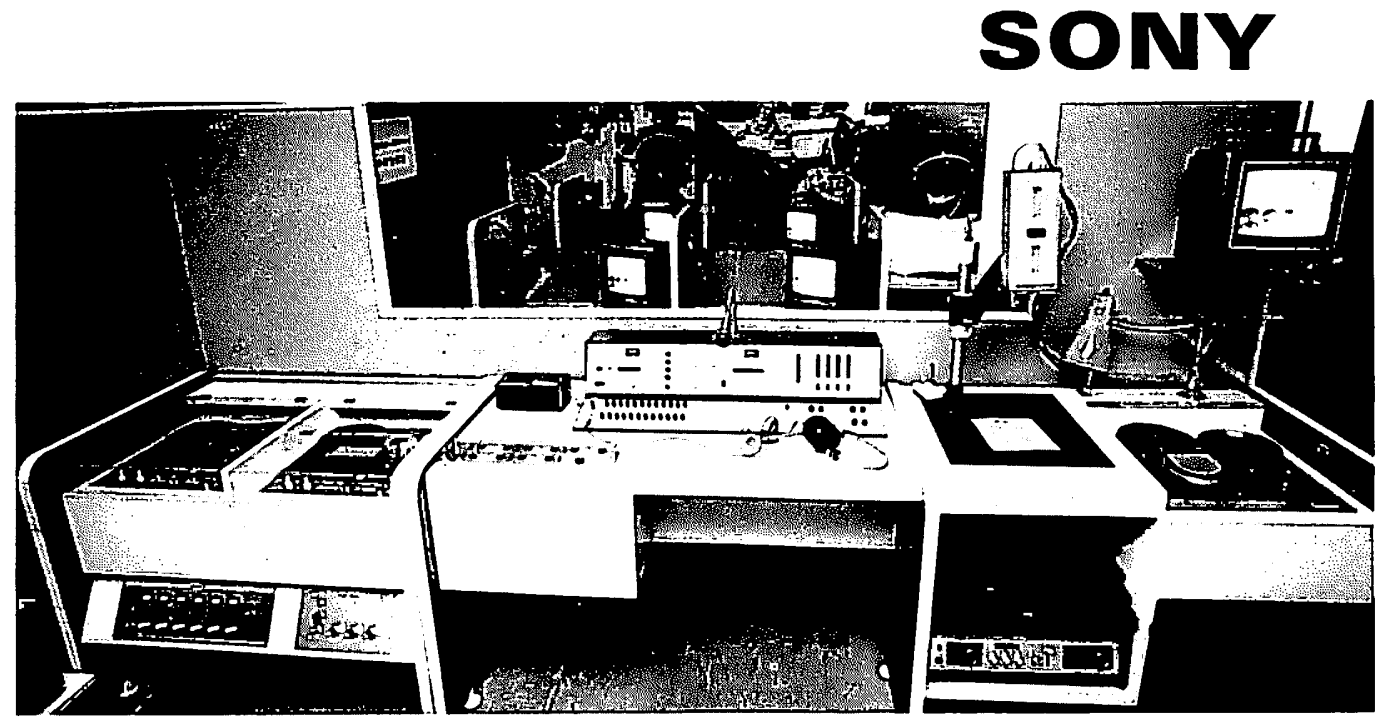


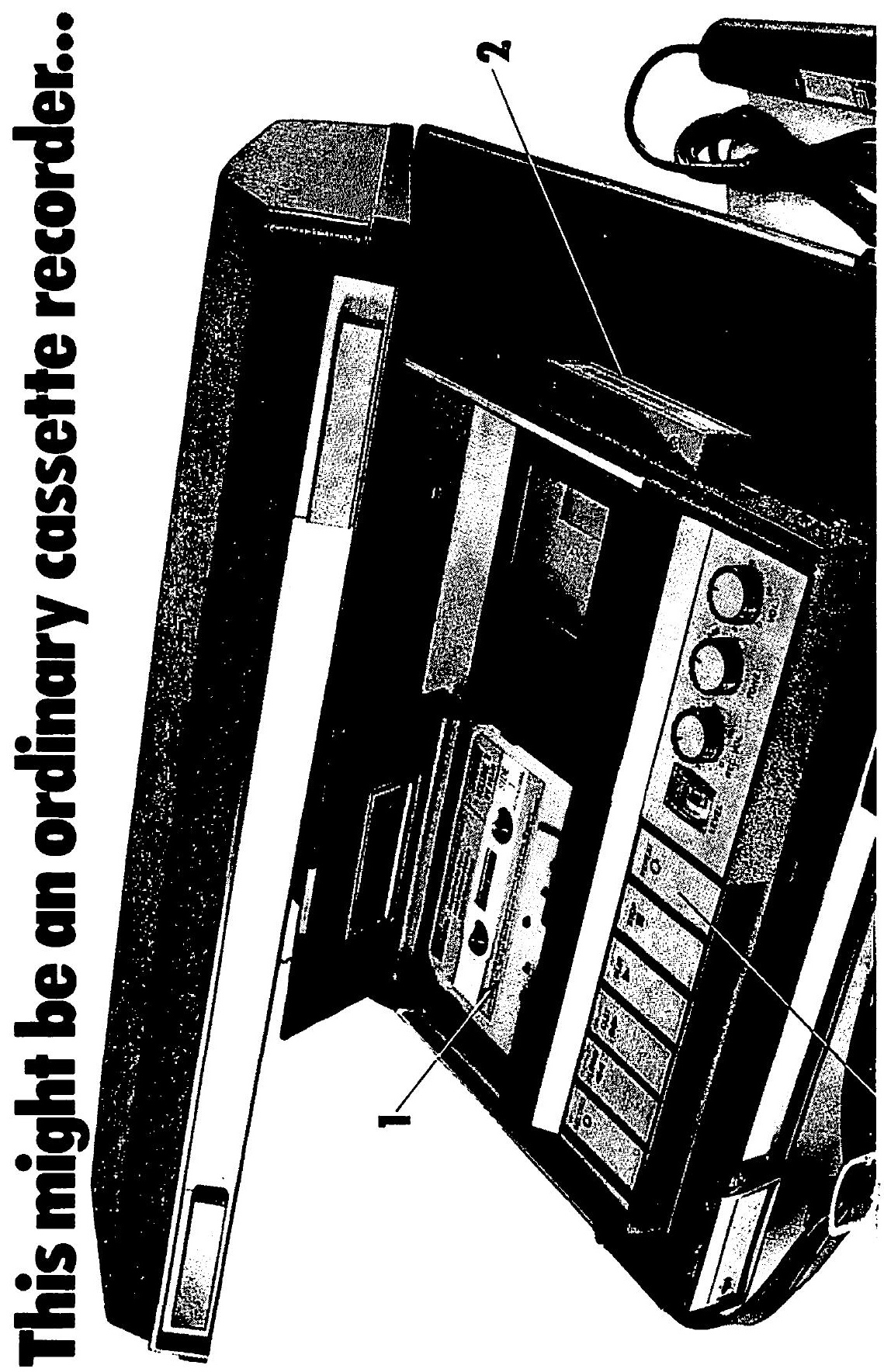




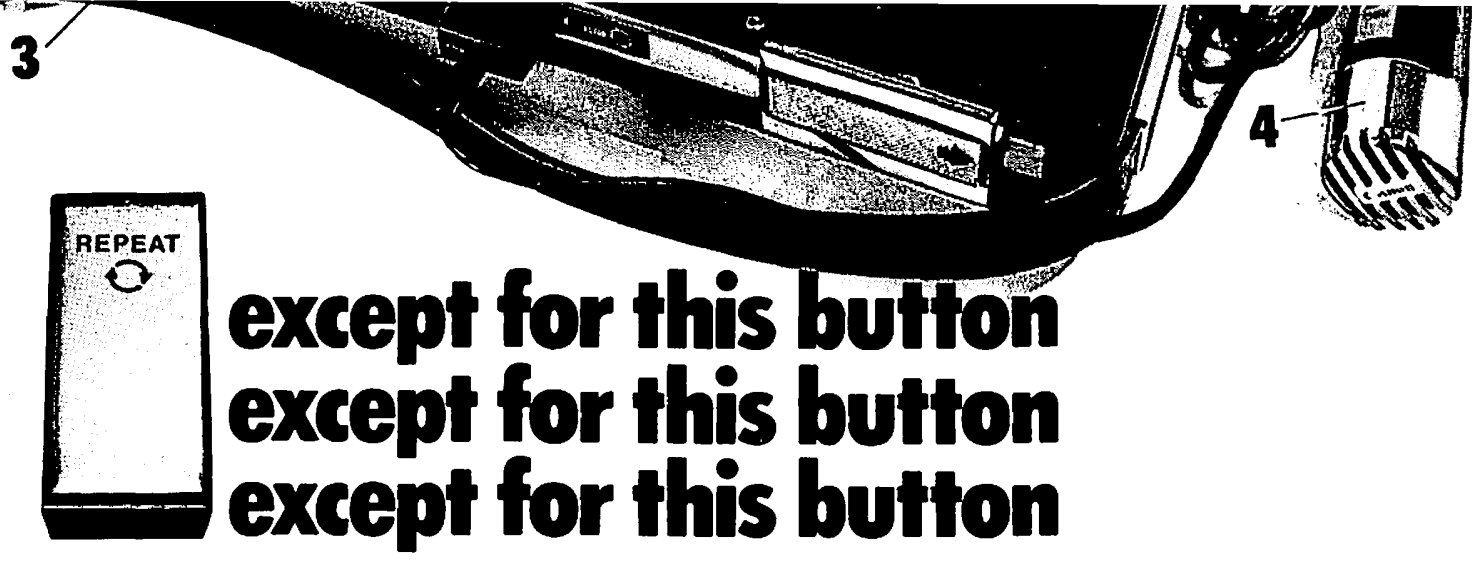

This REPEAT button helps people learn ... helps people learn ... helps people learn. Because beneath it is a whole new idea in teaching machines: the Canon REPEAT-CORDER L.

The REPEAT-CORDER L looks like an ordinary cassette tape recorder. In fact, it records and plays back cassettes exactly as any recorder, and with excellent fidelity. But it does one thing no other recorder can do: it repeats any phrase or section of the tape continuously... automatically... at the touch of a single button. This takes the drudgery out of language lessons, music practice or transcription of dictated notes.

How? With a unique second cassette 4 in which a 2-track tape is coiled in an endless loop. This second cassette records continuously from the first so that a predetermined length of the material from the first cassette is always available on the second one. The length is determined by the choice of the second cassette, which is available in from 5 to 30 second sizes.

By depressing the REPEAT button, the user halts the first cassette and simultaneously begins a play-back from the second cassette. This play-back is repeated until the user depresses the PLAY button, resuming exactly where he left off on the first cassette.

While the REPEAT-CORDER $L$ is repeating, the student may record ... and this too is repeated, so he can compare his accent with the instructor's, his music with the original. He may re-record as often as he wishes, until he is satisfied and presses the PLAY button to continue.
Suggested Educational Net $\$ 179.50$

REPEAT-CORDER L
Repeat-Corder Division,
Canon U.S.A., Inc., 64-10 Queens BIvd.,
Woodside, N.Y. 11377
Please send me more information on the
Canon Repeat-Corder L.
Name
Oritle
Organization



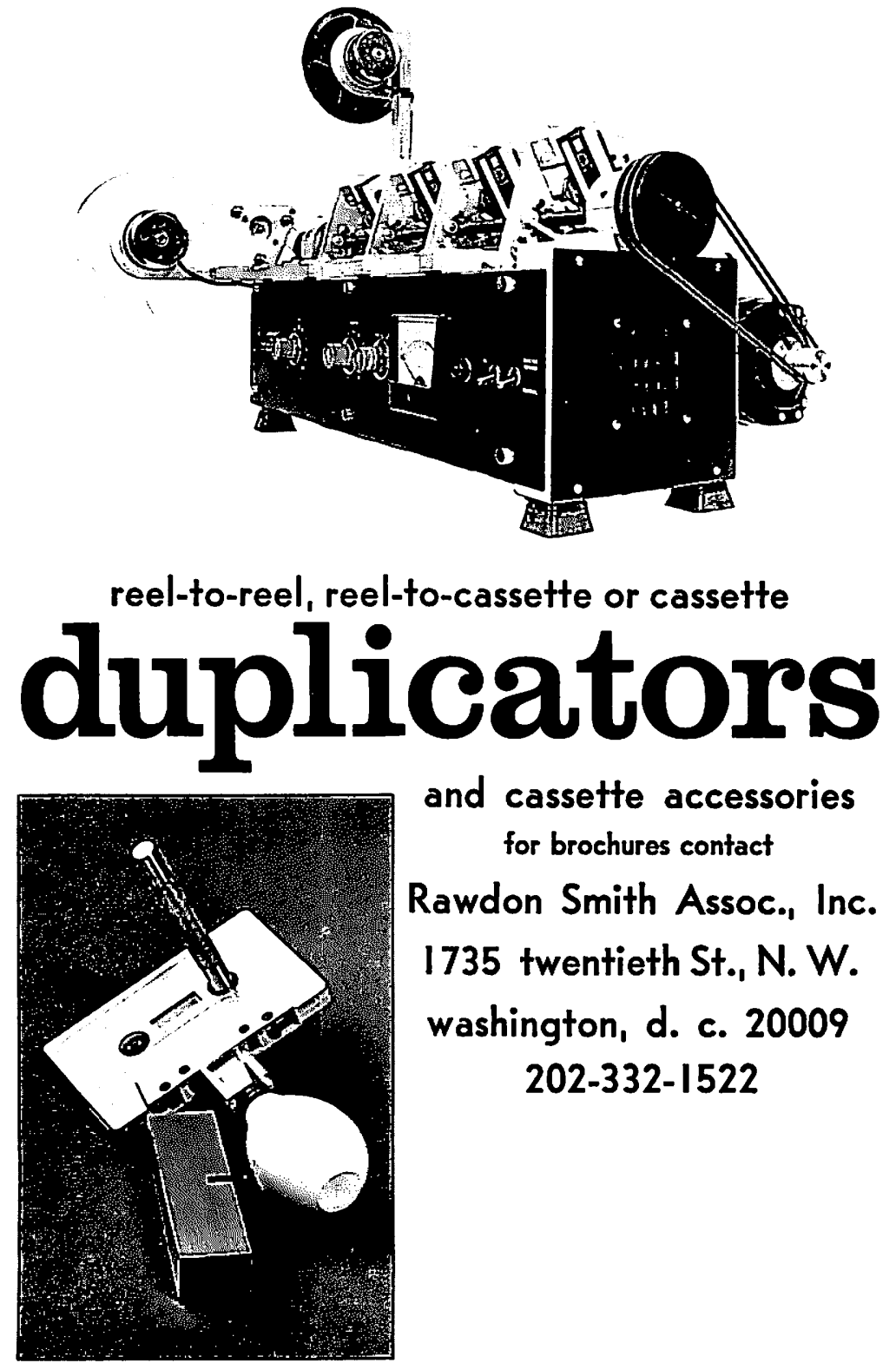

for brochures contact

Rawdon Smith Assoc., Inc. 1735 twentieth St., N. W. washington, d. c. 20009 202-332- 1522 


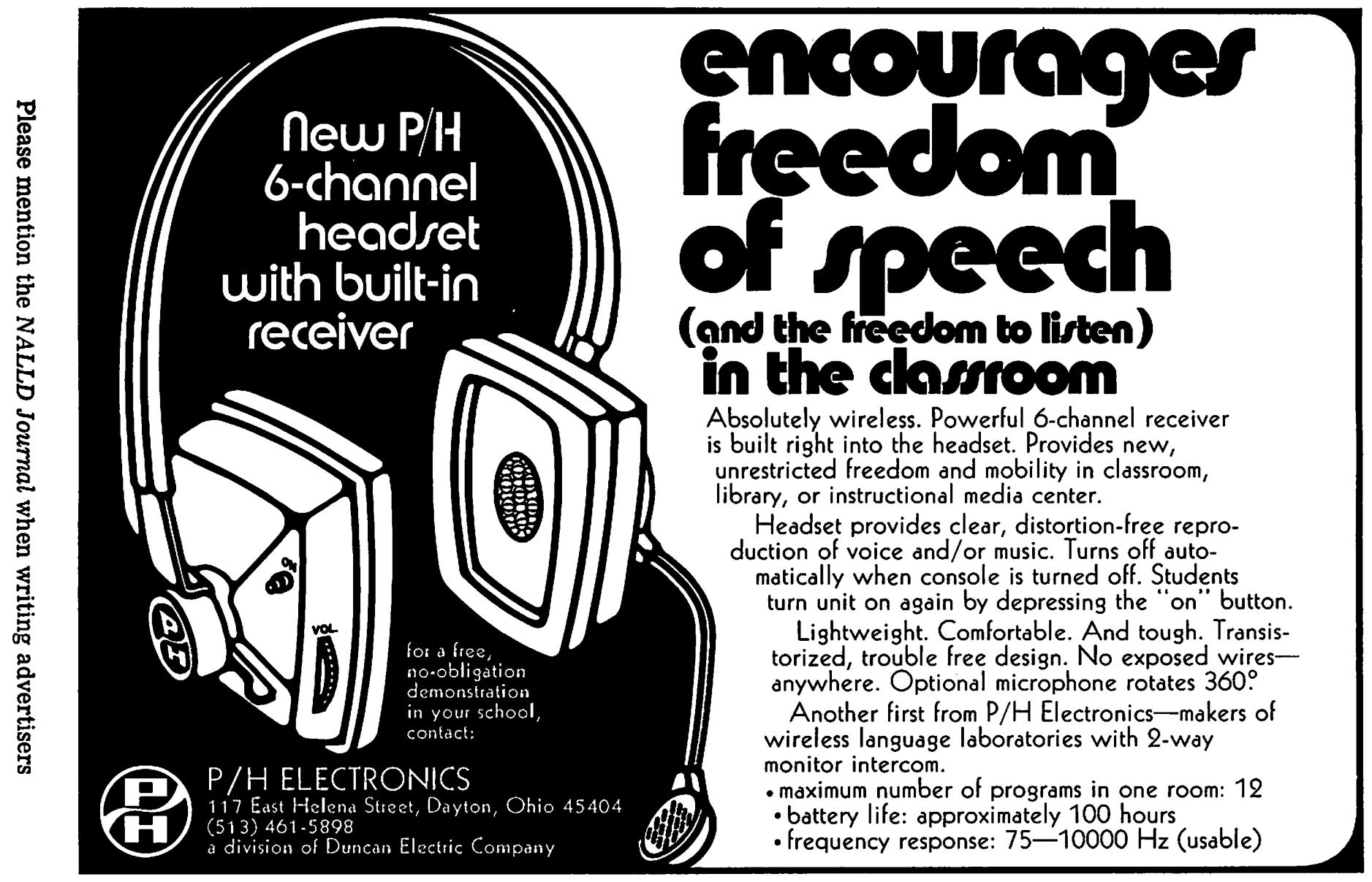




\section{RHEEM \\ CALIFONE}

for the best in

Language Labs

to accommodate groups

of any size or for

individual instruction

in listening/learning

situations

Write for complete information

(R⿴囗十)



Division of Rheem Manufacturing Co.

5922 Boweroft Avenue, Los Angeles 90016.

Please mention the NALLD Journal when writing advertisers 